\title{
Mininge
}

\section{Development of ball mill test for simulation of industrial circuit}

http://dx.doi.org/10.1590/0370-44672015690001

\section{Wellington Lacerda Gomes}

Pós-Graduando em Engenharia Mineral

Escola Politécnica - Universidade de São Paulo

São Paulo - SP - Brasil

wellingtonlacerdagomes@gmail.com

\section{Homero Delboni Júnior}

Professor

Departamento de Engenharia de Minas e de Petróleo Escola Politécnica - Universidade de São Paulo São Paulo - SP - Brasil

$\underline{\text { hdelboni@usp.br }}$

\section{Ana Carolina Chieregati}

Professora

Departamento de Engenharia de Minas e de Petróleo Escola Politécnica - Universidade de São Paulo

São Paulo - SP - Brasil

ana.chieregati@gmail.com

\section{Thiago Luis Alves Jatobá}

Pós-Graduando em Engenharia Mineral, Escola Politécnica - Universidade de São Paulo São Paulo - SP - Brasil tjatonline@gmail.com

\section{Introduction}

The main method used for designing ball mills was proposed by Bond (1952). Despite the wide application in traditional comminution circuits, this method shows limitations for its application.

Due to the limitations of the Bond method for designing industrial grinding circuits, simulation using phenomenological mathematical models has been increasingly used for projects destined to design and to improve the ball mill performance. The simulation method also allows assessing the integrated performance of comminution circuits. By determining the interaction among different circuit units, simulation is widely used for enhancing performances, as well

\begin{abstract}
The Bond method for ball mil designing has been used for 60 years. Based on the Work Index test, such method is applied mostly in traditional circuit configuration, which includes multi-staged crushing, followed by rod and ball milling. On the other hand, simulation is a widespread and used technique for comminution, classification modeling, and simulation. Even though both methods are complementary, there is no effective integration between them. This work shows a technique designed to integrate both energy and modeling approaches for estimating and improving ball mill grinding performance. The work is based on industrial data survey results, as well as on laboratory testing, the latter developed specifically for such a purpose. The technique was validated under an industrial environment for assessing the obtained results.
\end{abstract}

keywords: grinding; modeling; simulation.

as carrying out full circuit mass balances, which is not possible with the Bond method.

The Perfect Mixing Model (PMM) as proposed by Whiten (1976) is a widespread method for grinding modelling and simulation. It followed the Population Balance Model (PBM) developed by Epstein (1947). PMM is based on a steady-state balance among particle size fractions within the mill load, the latter considered as perfectly mixed.

Even though very flexible, PMM depends upon retro-fitting for creating realistic simulation scenarios. The situation is particularly difficult in greenfield projects where virtually no specific data is available. In this case, a pilot plant may be an option, even though it normally requires a relatively large number of ore samples, which may not be available. Moreover, a scale-up procedure has to be established for predicting industrial ball mill performance as compared with corresponding pilot plant units. In such circumstances, bench scale testing significantly reduces the amount of required material for testing but does not solve the scale-up limitation.

This study aimed at developing a method from a laboratory grinding test that allows direct usage of mathematical modelling and simulation with no scale-up procedures to estimate and to improve the performance of industrial ball milling circuits. 


\section{Method and materials}

Three different industrial grinding circuits were surveyed for developing the present method. The first included a traditional multi-staged crushing circuit followed by ball milling at Mineração Serra Grande (MSG). The second was comprised of multi-staged crushing, followed by rod milling and ball milling at VALE Fertilizantes - Araxá (VALE), while the third involved semi-autogenous grinding (SAG) milling, followed by ball milling at Mineração Mirabela (Mirabela).

In each case, the corresponding industrial grinding circuit was surveyed for obtaining size distributions and percent

\begin{tabular}{c|c|c|c|c|c|c} 
Variable & Test 1 & Test 2 & Test 3 & Test 4 & Test 5 & Test 6 \\
\hline Ball mill type & Lifters & Lifters & Lifters & Lifters & Lifters & $\begin{array}{c}\text { Non- } \\
\text { lifters }\end{array}$ \\
\hline \% Critical speed & 72 & 75 & 69 & 72 & 72 & 72 \\
\hline $\begin{array}{c}\text { Ball top size } \\
(\mathrm{mm})\end{array}$ & 38 & 38 & 38 & 30 & 25 & 38 \\
\hline
\end{tabular}

Samples obtained in each one of the three surveys were used for six bench-scale tests, undergoing different

operations as described in Table 1. In each case the individual test included three grinding periods ie. 15, 30 and 45

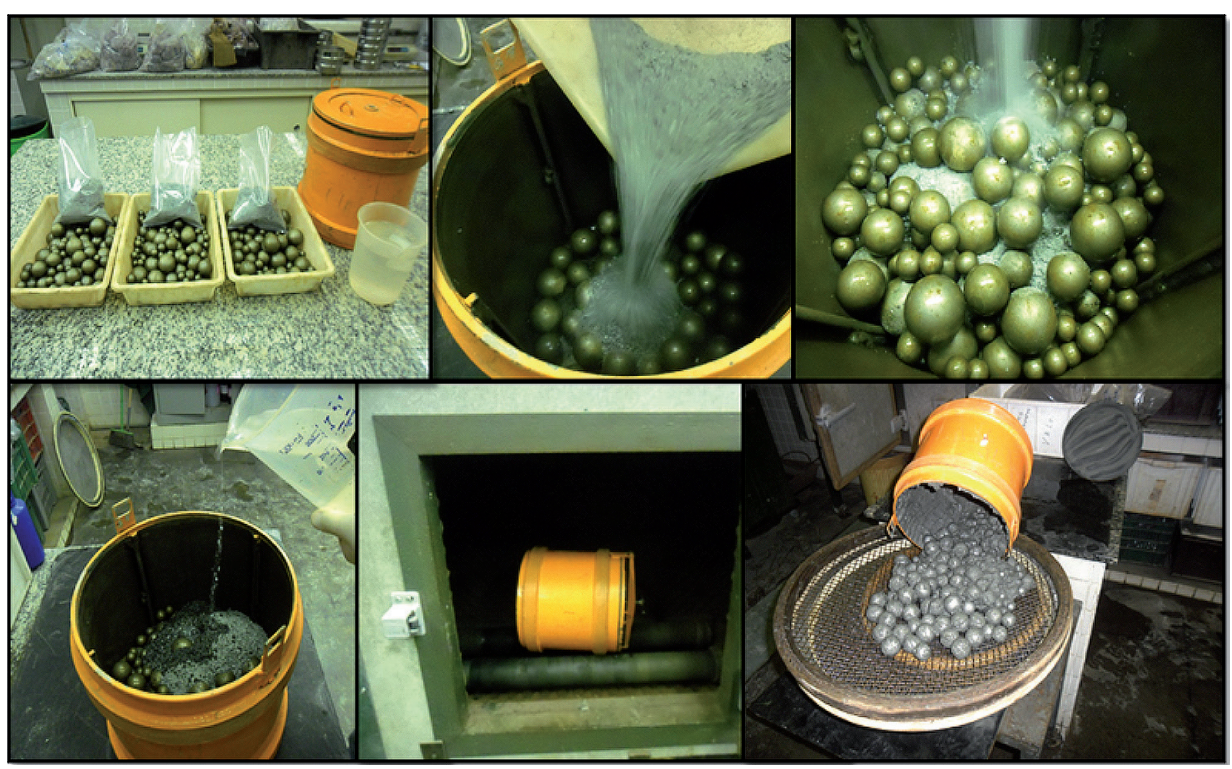

Testing results were used to calibrate the PMM, according to different operating conditions. Simulations were then carried out for predicting the respective industrial grinding circuit based on the corresponding test. In this case the simulations took into account grinding circuit fresh feed and product, the latter being comprised of of solids in individual streams, as well as operating data and ore characterization indices. Based on such data, full mass balancing was carried out for obtaining consistent flowrates and size distributions around the circuit.

Samples obtained in survey campaigns were then used to perform bench-scale grinding tests. The sample preparation started with staged crushing and screening to obtain a $-3.35 \mathrm{~mm}$ (6\# Tyler) product. It was followed by homogenization and quartering procedures. Head samples were used for determining test performed.
Table 1

Laboratory tests grinding ball mill operating conditions.

minutes, summing up 54 tests. Figure 1 illustrates the procedures adopted for grind tests.
Figure 1

Test grinding ball mill sequential procedure.

the energy required to generate mass $(t)$ at specific size (mesh). Bench-scale mill power was estimated by Morrell model (Morrell, 1996a, 1996b).

Table 2 shows ball top sizes for surveyed industrial circuits, as well as respective ball mill power that was measured during the sampling period, as compared with bench-scale tests. 


\begin{tabular}{|c|c|c|c|c|c|c|c|c|c|c|}
\hline & Variable & Test 1 & Test 2 & Test 3 & Test 4 & Test 5 & Test 6 & MSG & VALE & Mirabela \\
\hline & Power (kW) & 0,0808 & 0,085 & 0,0767 & 0,0808 & 0,0808 & 0,0808 & 936 & 2.765 & 11.447 \\
\hline Table 2 & $\begin{array}{l}\text { Ball top size } \\
\quad(\mathrm{mm})\end{array}$ & 38 & 38 & 38 & 30 & 25 & 38 & 60 & 60 & 63 \\
\hline
\end{tabular}

Figure 2 shows a detailed flowchart for procedures adopted throughout the described testing.

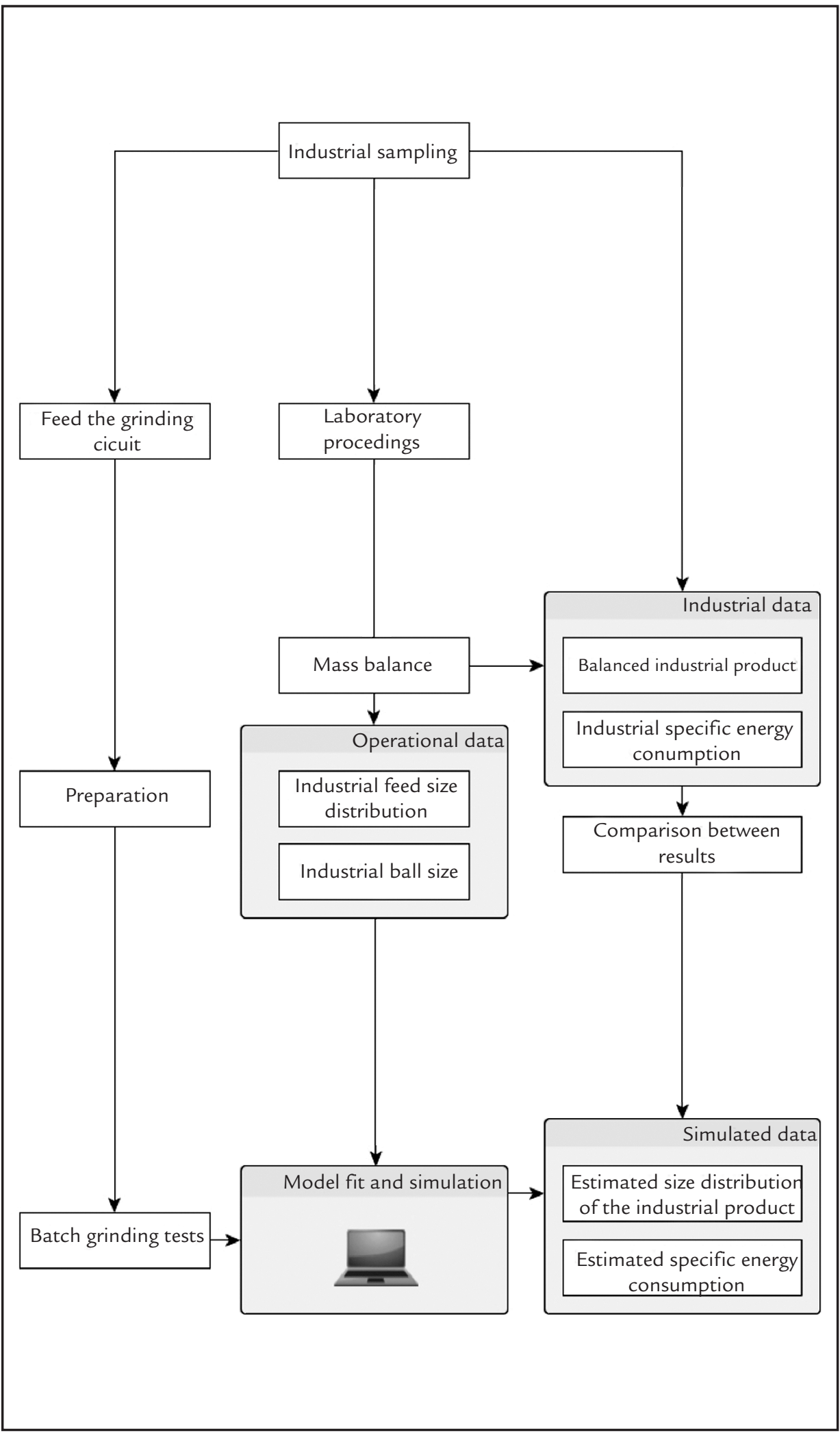

Sequential activities flowchart. 


\section{Results}

Bench-scale tests carried out with all MSG, VALE and Mirabela samples indicated that the 15-minute grinding pe-

riod was the most adequate for predicting the respective product size distributions (hydrocyclone overflow).

\section{Prediction of industrial circuit product size distribution}

Figure 3 shows graphs for comparing simulated and bench-scale testing particle size distributions.
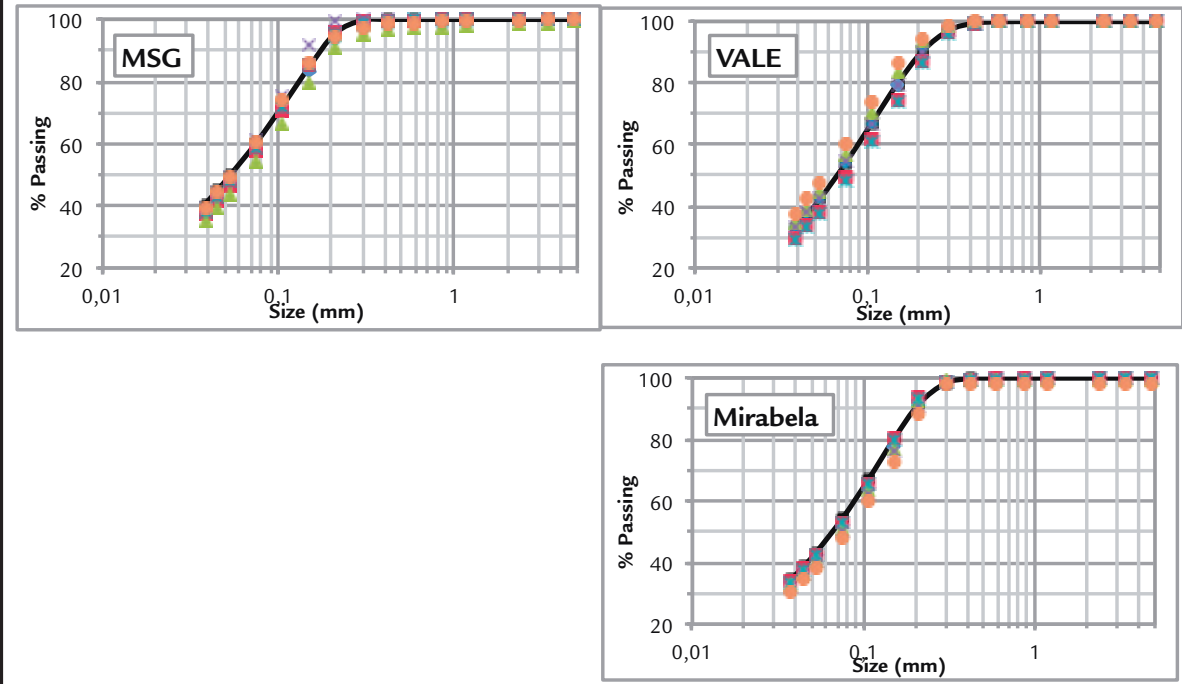

$\rightarrow-$ Industrial $\bullet$ Test $1 \backsim$ Test $2 \wedge$ Test $3 \times$ Test $4 *$ Test $5 \bullet$ Test 6
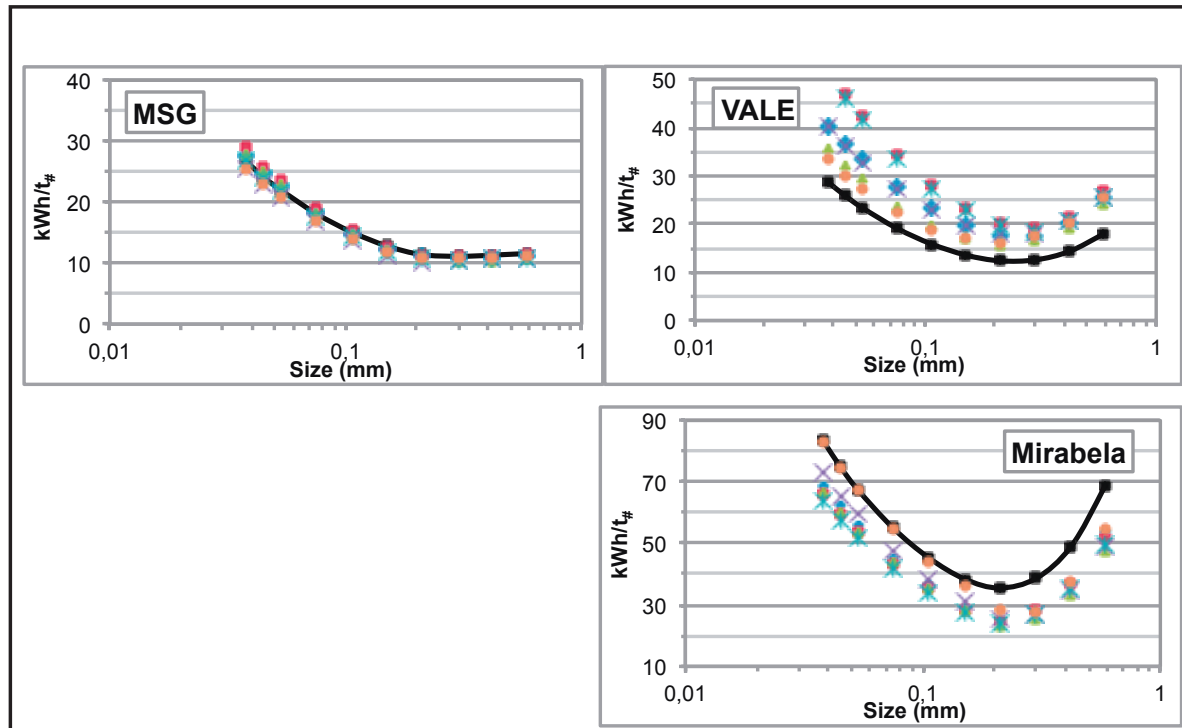

Industrial * Test $1 \backsim$ Test $2 \wedge$ Test $3 \times$ Test $4 *$ Test $5 \bullet$ Test 6

\section{Discussion}

Dissimilarity matrices were used to analyse obtained results, according to which Euclidian distances between simulated and bench-scale results were calculated for all three studied industrial circuits. The index represents the square root of the sum of differences among the values to be compared, ie. size distributions and specific energy consumption at a
Figure 3

Comparing simulated and bench-scale testing particle size distributions.

Figure 4

Comparing simulated and bench-scale specific energy predictions.

specific size fraction.

Table 3 shows dissimilarity matrices with respective Euclidian distances comparing simulated and bench-scale testing particle size distributions. 
Table 3

Dissimilarity matrix with

Euclidian distances - Size distribution.

Table 3 indicates that Test 4 showed the best estimations for size distributions, with 18.4 total Euclidian distance, whereas Test 6 showed the worst estimation, the latter with 34.8 total Euclidian distance. Tests 1, 2 and 5 also showed good estimates, as indicated by total Euclidian distances of 20.0; 21.1 and 20.7 respectively.

Mill rotating speed, ball top size

Table 4

Dissimilarity matrix with Euclidian distances - Specific energy consumption.

Table 4 indicates that Test 6 showed the best results, with a total Euclidian distance of 40.4 .

Here too, the specific energy consumption estimative was separately investigated for the optimum ball size, mill rotating speed and lifted/smooth

\section{Method Developed}

As described in the previous section, Tests 4 and 6 were selected for predicting respectively particle size distribution and specific energy consumption. However, a more robust approach would include single test conditions for industrial ball milling performance predictions. In this regard, Test 6 was the selected one.

Standard conditions thus include approximately $3 \mathrm{~kg}$ of the ore for

\begin{tabular}{c|c|c|c|c|c|c} 
Industrial Circuit & Test 1 & Test 2 & Test 3 & Test 4 & Test 5 & Test 6 \\
\hline MSG & 10,0 & 6,57 & 16,5 & 8,42 & 4,39 & 3,98 \\
\hline VALE & 2,12 & 11,3 & 7,63 & 1,16 & 13,1 & 15,3 \\
\hline Mirabela & 7,87 & 3,24 & 7,42 & 8,87 & 3,18 & 15,5 \\
\hline Total & 20,0 & 21,1 & 31,5 & 18,4 & 20,7 & 34,8 \\
\hline
\end{tabular}

and lifter aspects were also used for comparing size distribution test results. Test 1 indicated that $72 \%$ of the critical speed resulted in the best results, while Test 4 indicated that $30 \mathrm{~mm}$ ball top size resulted in the best results for such an aspect. Tests with charge lifters resulted in better results when compared with corresponding tests with a smooth mill shell.

\begin{tabular}{c|c|c|c|c|c|c} 
Industrial Circuit & Test 1 & Test 2 & Test 3 & Test 4 & Test 5 & Test 6 \\
\hline MSG & 1,74 & 3,27 & 2,43 & 3,85 & 1,96 & 3,02 \\
\hline VALE & 25,7 & 45,6 & 16,5 & 25,1 & 43,1 & 14,9 \\
\hline Mirabela & 36,7 & 41,7 & 45,2 & 35,2 & 47,0 & 22,5 \\
\hline Total & 64,1 & 90,5 & 64,2 & 64,1 & 92,0 & 40,4 \\
\hline
\end{tabular}

mill shell.

Tests 1 and 3 indicated that $72 \%$ and $69 \%$ of the critical speed resulted in best results, as well as Tests 1 and 4 indicated that $38 \mathrm{~mm}$ and $30 \mathrm{~mm}$ optimum ball size resulted in the best results for such an aspect. Test with no charge lifters resulted
Therefore, the best combination for predicting size distributions included bench-scale testing at $72 \%$ critical speed, $30 \mathrm{~mm}$ optimum ball size and mill shell provided with lifters.

Table 4 shows a dissimilarity matrix with comparative Euclidian distances between specific energy consumption estimated by simulated and bench-scale testing. in better results when compared with corresponding tests with a smooth mill shell.

Therefore, the best combination for predicting specific energy included bench-scale testing at $72 \%$ critical speed, $30 \mathrm{~mm}$ optimum ball size and mill shell with no lifters. testing. Initial preparation consists in staged crushing in a roll crusher and screening, for obtaining a $-3.35 \mathrm{~mm}$ (6\# Tyler) product. The test should be conducted on a 10 " in length and diameter 1020 steel carbon mill shell at $70 \%$ solids, 33\% load fraction, $72 \%$ critical speed and $38 \mathrm{~mm}$ optimum ball size. Grinding time is set at 15 minutes.

The resulting feed and product size distributions are used to calibrate the PMM by varying optimum ball size. Actual fresh feed should be used in the calibrated model for simulating the calibrated industrial ball mill model and should include product simulation to provide an estimation of the industrial product. Specific energy consumption is based on simulation results, as well as on the power model. 


\section{Conclusions}

Based on bench-scale tests, a method for predicting industrial ball milling was developed. The model was based on three different industrial grinding operations including traditional multi-staged crushing followed by ball milling, traditional multi-staged crushing followed by rod milling and ball milling, as well as SAG and ball milling circuit configuration.

Based on bench-scale standard testing, the PMM is calibrated for representing selected test conditions. Such model is also calibrated for predicting industrial ball milling performance in terms of both product size distribution and specific energy consumption. Although the specific energy consumption estimated by batch grinding tests was significantly different for VALE (traditional multi-staged crushing followed by rod milling and ball milling) and Mirabela (SAG and ball milling circuit), detailed investigation is being conducted to better understand this question.

\section{Acknowledgements}

Thanks to team of Mineração Serra Grande, Mineração VALE Fertilizantes - Unidade Araxá e Mineração Mirabela.

\section{References}

BOND, F. C. The third theory of comminution. Transactions AIME, May 1952. p. 484-494.

EPSTEIN, B. The material description of certain breakage mechanisms leading to the logorithmic-normal distribution. J. Franklin Inst, 1947.

MORRELL, S. Power draw of wet tumbling mills and its relationship to charge dynamics - Part 1: a continuum approach to mathematical modeling of mill power draw. Trans Inst Min Metall, January-April, 1996a.

MORRELL, S. Power draw of wet tumbling mills and its relationship to charge dynamics - Part 2: an empirical approach to modelling of mill power draw. Trans Inst Min Metall, January-April, 1996b.

MORRELL, S., MAN, Y. T. Using modelling and simulation for the design of full scale ball mill circuits. Minerals Engineering, Oxford. v. 10, n. 12, p. 1311-1327, 1997.

WHITEN, W. J. Ball mill simulation using small calculators. Proceedings AusIMM. p. 47-53, 1976.

Received: 05 January 2015 - Accepted: 14 July 2015. 